\title{
Comparison of the SmaI-Digested Chromosomes of Staphylococcus epidermidis and the Closely Related Species Staphylococcus capitis and Staphylococcus caprae
}

\author{
CAROL G. GEORGE* AND WESLEY E. KLOOS \\ Department of Genetics, North Carolina University, Raleigh, North Carolina 27695-7614
}

\begin{abstract}
Pulsed-field gel electrophoresis was used to examine the chromosomal polymorphisms existing within and between four closely related members of the Staphylococcus epidermidis species group, S. epidermidis, Staphylococcus caprae, Staphylococcus capitis subsp. capitis, and $S$. capitis subsp. ureolyticus. SmaI was chosen as the restriction endonuclease for this study because it generated only a few well-separated chromosomal fragments. Each of the species and subspecies showed distinct SmaI digest patterns. The strains examined in this study were collected over a 20-year period from various geographical locations. The results indicate that DNA fragment patterns are unique to each species and subspecies and represent a reasonably stable component in the chromosome structure. $S$. caprae and $S$. capitis demonstrated considerable conservation in chromosome structure as indicated by the large numbers of conserved SmaI digest fragments. The polymorphisms found within each species appear to be linked to the species' character variability. The genome size of each Staphylococcus strain was extrapolated from the SmaI digest fragment pattern obtained by pulsed-field gel electrophoresis. The average genome size for $S$. epidermidis is $2,364 \pm 119 \mathrm{~kb}$; for $S$. caprae strains from humans it is $2,600 \pm 157 \mathrm{~kb}$ and for $S$. caprae strains from goats it is $2,493 \pm 15 \mathrm{~kb}$; for $S$. capitis subsp. capitis it is 2,456 $\pm 71 \mathrm{~kb}$; and for $S$. capitis subsp. ureolyticus it is $2,276 \pm 90 \mathrm{~kb}$.
\end{abstract}

The genus Staphylococcus has been organized into 32 species comprising at least six species groups $(5,15,23,24)$. Phylogenetic relationships have been suggested by DNA-DNA hybridization and supportive phenotypic tests (15). Recently, pulsedfield gel electrophoresis (PFGE) has been used to examine number of different polymorphisms found in each species is linked to that species' genetic variability. For staphylococci, several different restriction endonucleases have been examined by us and others $(18,21)$ for the purpose of obtaining a small number of well-spaced chromosome fragments to provide a

\% DNA - DNA homology

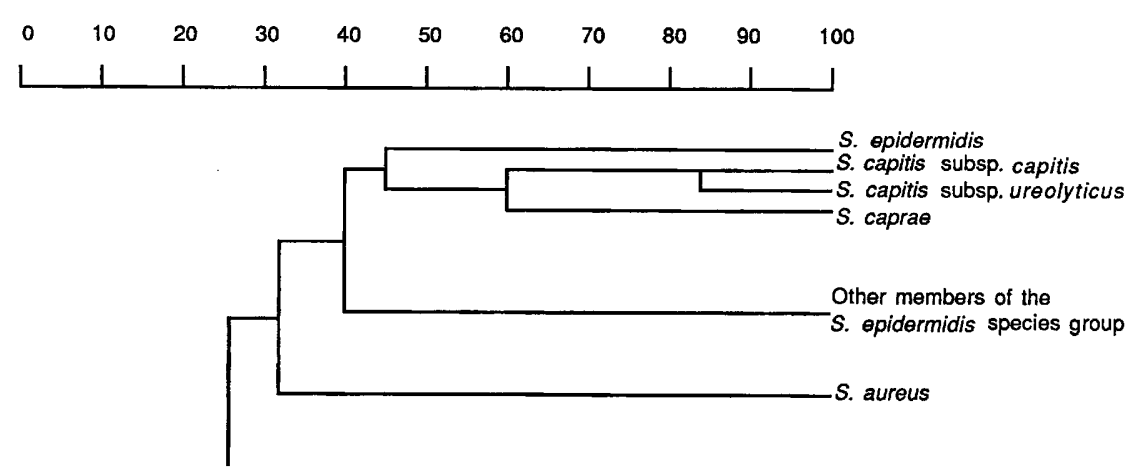

FIG. 1. Dendrogram of the phylogenetic relationships among $S$. epidermidis, $S$. caprae, $S$. capitis subsp. capitis, and $S$. capitis subsp. ureolyticus based on optimal DNA-DNA reassociation conditions.

chromosomal polymorphisms existing within and between bacterial species $(2,18,21)$. Chromosomal polymorphisms relate to differences in the numbers and sizes of specific fragments of genomic DNA that are generated by restriction enzymes. The

\footnotetext{
${ }^{*}$ Corresponding author. Phone: (919) 515-5787. Fax: (919) 515-
} 3355 . readable DNA profile. The restriction endonuclease SmaI was selected because this enzyme generates only 17 to 28 chromosome fragments, most of which are widely spaced.

In this study, SmaI digestion and PFGE were used to examine the chromosomal polymorphisms of four closely related members of the Staphylococcus epidermidis species group (Fig. 1), S. epidermidis, Staphylococcus caprae, Staphylococcus capitis subsp. capitis, and $S$. capitis subsp. ureolyticus (15), to estimate the extent of variability found within each 
TABLE 1. List of Staphylococcus strains and their isolation dates, sources, and locations

\begin{tabular}{|c|c|c|c|}
\hline $\begin{array}{l}\text { Species, subspecies, and } \\
\text { strains }\end{array}$ & $\begin{array}{l}\text { Host or } \\
\text { source }\end{array}$ & Location $^{a}$ & Isolation date \\
\hline \multicolumn{4}{|l|}{ S. epidermidis } \\
\hline MAW 815 & Human & Raleigh, N.C. & 1981 \\
\hline MAW $815(91)$ & Human & Boone, N.C. & 1991 \\
\hline MAW 8111 & Human & Raleigh, N.C. & 1981 \\
\hline MAW 8114 & Human & Raleigh, N.C. & 1981 \\
\hline CJ 879 & Human & Fayetteville, N.C. & 1987 \\
\hline CJ 877 & Human & Fayetteville, N.C. & 1987 \\
\hline CJ 8726 & Human & Fayetteville, N.C. & 1987 \\
\hline CB $877-4$ & Human & Fayetteville, N.C. & 1987 \\
\hline CB 877-6 & Human & Fayetteville, N.C. & 1987 \\
\hline CB 8712 & Human & Fayetteville, N.C. & 1987 \\
\hline MR 8718 & Human & Fayetteville, N.C. & 1987 \\
\hline MR 8719 & Human & Fayetteville, N.C. & 1987 \\
\hline MR 8711 & Human & Fayetteville, N.C. & 1987 \\
\hline \multicolumn{4}{|l|}{ S. caprae } \\
\hline 142.22 & Goat milk & Nouzilly, France & $1980 \mathrm{~s}$ \\
\hline 141.15 & Goat milk & Nouzilly, France & $1980 \mathrm{~s}$ \\
\hline 143.15 & Goat milk & Nouzilly, France & $1980 \mathrm{~s}$ \\
\hline 2122 & Human & Oklahoma City, Okla. & 1991 \\
\hline $\mathrm{H} 2132$ & Human & Columbus, Ohio & $1990 \mathrm{~s}$ \\
\hline UHL 2455 & Human & London, Ontario, Canada & $1990 \mathrm{~s}$ \\
\hline G15752 & Human & Columbus, Ohio & $1990 \mathrm{~s}$ \\
\hline $\mathrm{T} 11022$ & Human & Columbus, Ohio & $1990 \mathrm{~s}$ \\
\hline G7344 & Human & Columbus, Ohio & $1990 \mathrm{~s}$ \\
\hline 3051 & Human & Chicago, Ill. & 1991 \\
\hline B3300 & Human & Columbus, Ohio & $1990 \mathrm{~s}$ \\
\hline M8756 & Human & Columbus, Ohio & $1990 \mathrm{~s}$ \\
\hline 106 & Human & Vancouver, British Columbia, Canada & $1990 \mathrm{~s}$ \\
\hline \multicolumn{4}{|l|}{ S. capitis subsp. capitis } \\
\hline WK 811 & Human & Raleigh, N.C. & 1981 \\
\hline CJ 872 & Human & Fayetteville, N.C. & 1987 \\
\hline JLJ 853 & Human & Raleigh, N.C. & 1985 \\
\hline EK 11 & Human & North Branch Station, N.J. & 1973 \\
\hline MAW 913 & Human & Boone, N.C. & 1991 \\
\hline MAW 911 & Human & Boone, N.C. & 1991 \\
\hline CJ 874 & Human & Fayetteville, N.C. & 1987 \\
\hline LK 811 & Human & Raleigh, N.C. & 1981 \\
\hline HK 811 & Human & Raleigh, N.C. & 1981 \\
\hline CB 871 & Human & Fayetteville, N.C. & 1987 \\
\hline CB 872 & Human & Fayetteville, N.C. & 1987 \\
\hline CB 873 & Human & Fayetteville, N.C. & 1987 \\
\hline MR 875 & Human & Fayetteville, N.C. & 1987 \\
\hline \multicolumn{4}{|l|}{ S. capitis subsp. ureolyticus } \\
\hline MAW 8436 & Human & Raleigh, N.C. & 1984 \\
\hline CB 8735 & Human & Fayetteville, N.C. & 1987 \\
\hline CMM 8536 & Human & Raleigh, N.C. & 1985 \\
\hline DLB 8531 & Human & Raleigh, N.C. & 1985 \\
\hline NRC 8535 & Human & Raleigh, N.C. & 1985 \\
\hline CMM 8539 & Human & Raleigh, N.C. & 1985 \\
\hline AW 8127 & Human & Raleigh, N.C. & 1981 \\
\hline NRC 8533 & Human & Raleigh, N.C. & 1985 \\
\hline 3239 & Human & Raleigh, N.C. & 1990 \\
\hline 3069 & Human & Raleigh, N.C. & 1990 \\
\hline 1115 & Human & Raleigh, N.C. & 1989 \\
\hline Hartford-1 & Human & Hartford, Conn. & 1985 \\
\hline DEM 8530 & Human & Raleigh, N.C. & 1985 \\
\hline
\end{tabular}

${ }^{a}$ Location refers to the host's place of residence or the original location of the source.

member and to extrapolate their genome sizes. In this study, the use of PFGE as an epidemiological tool for identifying strains within each of the above-mentioned species and subspecies was also assessed.

\section{MATERIALS AND METHODS}

Bacterial strains. The Staphylococcus strains used in this study are listed in Table 1 . All strains of $S$. epidermidis and $S$. 


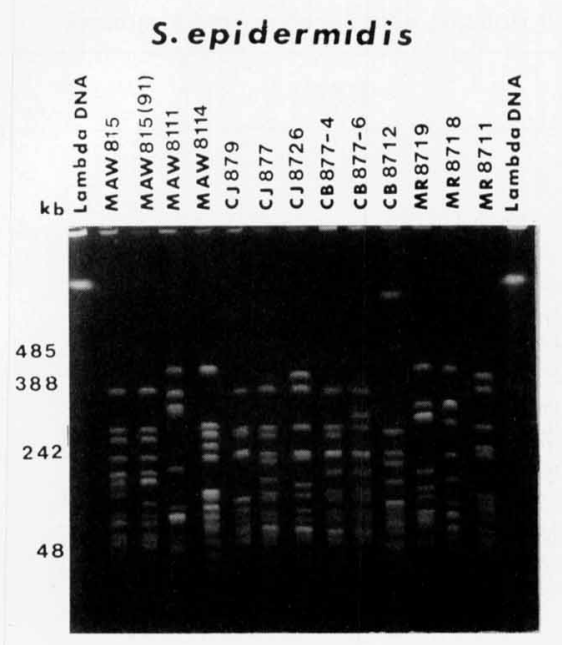

S. capitis subsp.capitis

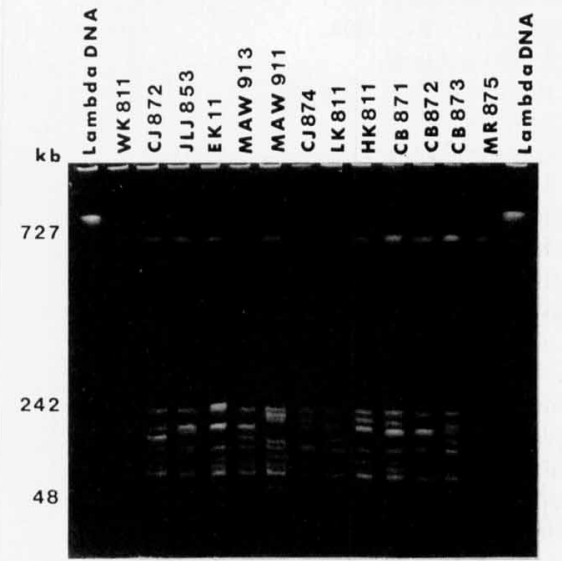

S. caprae

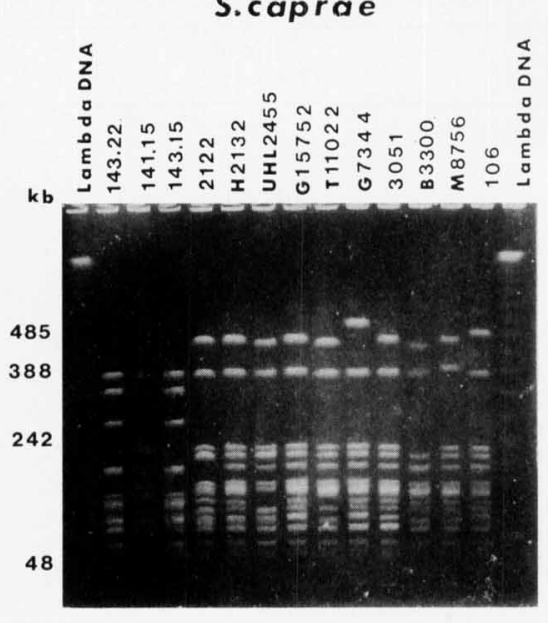

S. capitis subsp. ureolyticus

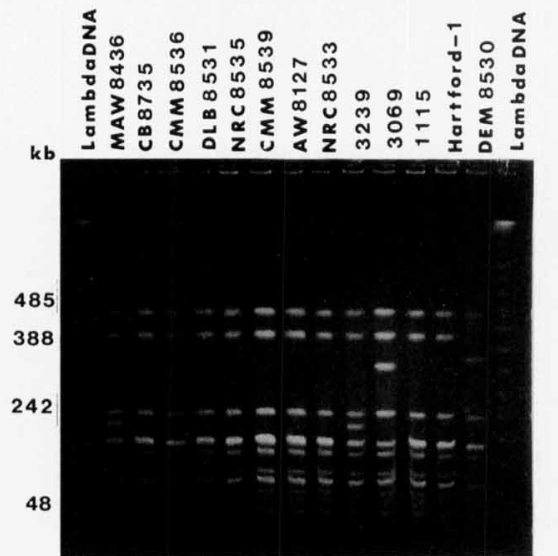

FIG. 2. PFGE of SmaI-digested, large genomic fragments of $S$. epidermidis, $S$. caprae, $S$. capitis subsp. capitis, and $S$. capitis subsp. ureolyticus strains.

capitis were isolated from humans. Ten strains of $S$. caprae were isolated from humans, and three strains of this species were isolated from goats. Species and subspecies identification was done according to the conventional methods of Kloos and coworkers $(11,13,15)$ and on the basis of original character descriptions $(3,6,14,22)$. The following strains were verified by DNA-DNA hybridization $(4,17)$ : $S$. epidermidis MAW 815 and MAW 8114; $S$. caprae 141.15, 2122, 3051, H2132, G15752, UHL 2455, and T11022 (hybridization kindly performed by T. L. Bannerman in our laboratory); S. capitis subsp. capitis WK811 and EK11; and $S$. capitis subsp. ureolyticus MAW 8436, CMM 8536, NRC 8533, DLB 8531, NRC 8535, and DEM 8530 (3). Individual strains were resolved on the basis of colony morphology, enzyme activities, carbohydrate reactions, antibiograms, plasmid composition, and plasmid restriction enzyme analysis $(13,15,17,19,20)$.

DNA preparation for PFGE analysis. DNA was prepared according to a modification of the procedures of Goering and Winters (8). Staphylococcus cultures were grown on the surface of a $\mathrm{P}$ agar medium $(14,16)$ for $18 \mathrm{~h}$ at $35^{\circ} \mathrm{C}$ as a source of inoculum. The overnight culture was transferred to $10 \mathrm{ml}$ of Trypticase soy broth (approximately $10^{7} \mathrm{CFU} / \mathrm{ml}$ ) and then shaken $(200 \mathrm{rpm})$ for $18 \mathrm{~h}$ at $35^{\circ} \mathrm{C}$. A portion of the overnight culture was diluted with Trypticase soy broth in a 3-ml cuvette until its optical density at $540 \mathrm{~nm}$ was between 0.7 and 0.8 . The same fraction of cells from the original overnight culture was then centrifuged in a Sorvall $\mathrm{RC} 2-\mathrm{B}$ centrifuge at 8,000 rpm for $10 \mathrm{~min}$, and the cell pellet was washed once and resuspended in $5 \mathrm{ml}$ of $0.1 \mathrm{M}$ Tris- $0.15 \mathrm{M} \mathrm{NaCl}-0.1 \mathrm{M}$ EDTA (TEN) buffer, $\mathrm{pH}$ 7.5. The cells were centrifuged again at $8,000 \mathrm{rpm}$ for 10 min and then resuspended in $2 \mathrm{ml}$ of $6 \mathrm{mM}$ Tris $\cdot \mathrm{Cl}-1 \mathrm{M}$ $\mathrm{NaCl}-100 \mathrm{mM}$ EDTA buffer containing $0.5 \%$ Brij 58, $0.2 \%$ deoxycholate, and $0.5 \%$ sodium lauroyl sarcosine (EC lysis buffer), $\mathrm{pH}$ 7.5. One milliliter of the cell suspension was transferred to a sterile $1.5-\mathrm{ml}$ microcentrifuge tube, to which was then added $50 \mu \mathrm{l}$ of lysostaphin solution $(1 \mathrm{mg} / \mathrm{ml}$ in 20 $\mathrm{mM}$ sodium acetate, $\mathrm{pH}$ 4.5) (recombinant lysostaphin [Ambicin L]; Applied Microbiology, Inc., New York, N.Y.). The tube was immediately vortexed, and then $1 \mathrm{ml}$ of cell suspension was removed and placed into $1 \mathrm{ml}$ of warm $\left(55^{\circ} \mathrm{C}\right) 2 \%$ low-gelling-temperature agarose (SeaPlaque; FMC, Rockland, Maine) prepared with EC lysis buffer. The agarose-cell suspension was immediately vortexed and transferred into a well of a 10-well sample plug mold (Bio-Rad, Hercules, Calif.). The agarose plug was cooled for $10 \mathrm{~min}$ at room temperature. The cooled agarose plug was removed from the mold with the aid of a small spatula and then transferred to $5 \mathrm{ml}$ of EC lysis buffer and incubated for approximately 1 to $2 \mathrm{~h}$ at $37^{\circ} \mathrm{C}$, until the plug was cleared (complete lysis). Following lysis, the EC lysis buffer was carefully decanted and replaced with $5 \mathrm{ml}$ of 10 


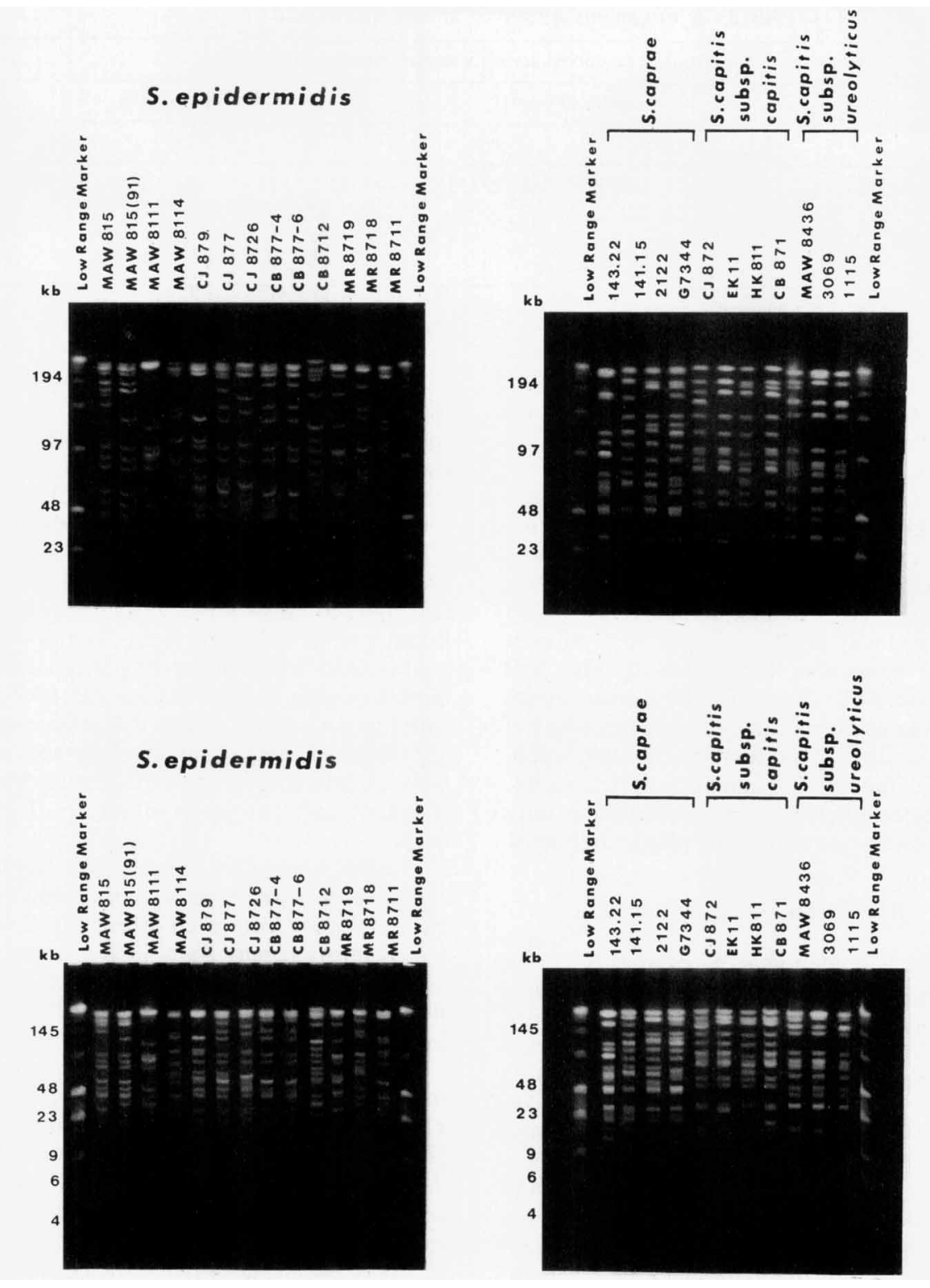

FIG. 3. PFGE of SmaI-digested, medium-size (upper panels) and small (lower panels) genomic fragments of S. epidermidis, S. caprae, S. capitis subsp. capitis, and $S$. capitis subsp. ureolyticus. Strains of $S$. caprae, $S$. capitis subsp. capitis, and $S$. capitis subsp. ureolyticus for which data are shown demonstrated different DNA fragment patterns. Those for which data are not included demonstrated the same fragment pattern as one of the strains for which data are shown did.

$\mathrm{mM}$ Tris $\cdot \mathrm{Cl}-1 \mathrm{mM}$ EDTA (TE) buffer, $\mathrm{pH}$ 7.6. The agarose plug in TE buffer was incubated at $55^{\circ} \mathrm{C}$ for $1 \mathrm{~h}$. The TE buffer was then decanted and replaced with $5 \mathrm{ml}$ of fresh TE buffer. The agarose plugs were stored at $4^{\circ} \mathrm{C}$ for up to 1 month.

SmaI digestion. Digestion of total DNA by the restriction endonuclease $S m a$ I was performed in a $1.5-\mathrm{ml}$ microcentrifuge tube by using a $125-\mu \mathrm{l}$ assay and $20 \mathrm{U}$ of enzyme according to the instructions of the manufacturer. The assay tube was vortexed and briefly centrifuged. A section ( 2 by 4 by $1.5 \mathrm{~mm}$ ) of the agarose plug prepared as described above was added to the assay tube and then incubated with shaking (150 rpm) for $2 \mathrm{~h}$ at $25^{\circ} \mathrm{C}$. After digestion, the agarose plug was removed from the assay tube and carefully placed into 1 well of a 15 -well $1 \%$ agarose (SeaKem GTG; FMC) gel slab (12.5 by 14 by 0.9 $\mathrm{cm}$ ) prepared with $0.5 \times$ Tris-borate-EDTA (TBE) buffer as previously described (8). The agarose plug was positioned against the forward wall of the well with the aid of a small spatula. Then the plug was sealed in the well with $0.8 \%$ low-gelling-temperature agarose prepared with $0.5 \times$ TBE buffer.

PFGE procedures and analysis. SmaI digest fragments were separated in the agarose gel slab by using a Bio-Rad CHEF-DR II pulsed-field electrophoresis unit. Electrophoresis was performed in $0.5 \times$ TBE buffer maintained at $14^{\circ} \mathrm{C}$. To identify the DNA fragments, which had a large range of sizes, three separate gels were run, each under different conditions. For the largest DNA fragments $(\geq 100 \mathrm{~kb}$ ), a gel was run with a ramped pulse of 15 to $55 \mathrm{~s}$ at $200 \mathrm{~V}$ for $22 \mathrm{~h}$. To identify the medium-size DNA fragments (50 to $100 \mathrm{~kb})$, a second gel was prepared and run with a ramped pulse of 1 to $10 \mathrm{~s}$ at $200 \mathrm{~V}$ for $20 \mathrm{~h}$. To identify the smallest DNA fragments (4 to $50 \mathrm{~kb}$ ), a third gel was prepared and run with a ramped pulse of 1 to 12 
TABLE 2. Fragments conserved among species and subspecies

\begin{tabular}{|c|c|c|c|c|c|c|c|c|c|}
\hline \multicolumn{10}{|c|}{ Fragment(s) $)^{a}$ conserved among indicated percentage of strains } \\
\hline \multicolumn{2}{|c|}{ S. epidermidis } & \multirow{2}{*}{ S. caprae (goat), $100 \%$} & \multicolumn{2}{|c|}{ S. caprae (human) } & \multicolumn{3}{|c|}{ S. capitis subsp. capitis } & \multicolumn{2}{|c|}{ S. capitis subsp. ureolyticus } \\
\hline $100 \%$ & $77 \%$ & & $100 \%$ & $90 \%$ & $100 \%$ & $92 \%$ & $77 \%$ & $100 \%$ & $92 \%$ \\
\hline 86,41 & $215,26,19$ & $\begin{array}{c}388^{b}, 170,120,118 \\
76,70,52,32^{b}, 28 \\
24^{b}, 22^{b}, 19,4\end{array}$ & $\begin{array}{c}214,140,130,50 \\
32,24,22,12\end{array}$ & $388,224,188$ & $\begin{array}{c}700,229,140 \\
89^{c}, 82^{c}, 64 \\
54^{c}, 35^{c}, 19^{c} \\
16,9,7^{c}, 5^{c}\end{array}$ & 194 & $120,102,97$ & $\begin{array}{l}463,240,175,148 \\
108,89,82,76 \\
67,54,45,35 \\
19,7,5\end{array}$ & 408 \\
\hline
\end{tabular}

${ }^{a}$ Fragments designated according to size in kilobases.

${ }^{b}$ Fragment shared by goat and human $S$. caprae strains

Fragment shared by both subspecies of $S$. capitis.

$\mathrm{s}$ at $150 \mathrm{~V}$ for $20 \mathrm{~h}$. The gels were stained with ethidium bromide $(2 \mu \mathrm{g} / \mathrm{ml})$ for $25 \mathrm{~min}$ and then destained in distilled water for $60 \mathrm{~min}$ to $24 \mathrm{~h}$.

The genome size of each strain was estimated from the sum of the SmaI digest fragments appearing on gels following PFGE. The lambda ladder DNA size standard (Bio-Rad) was used as a reference for determining the sizes of the largest SmaI digest fragments. The sizes of the smaller SmaI digest fragments were determined with the Low Range PFG Marker (New England Biolabs) molecular size standard. The Soft Laser Densitometer (model SLR-2D/ID; Bio Med Instruments Inc., Fullerton, Calif.) was used to scan Polaroid negatives of each ethidium bromide-stained gel to analyze the light intensity of each band and estimate the numbers of fragments. Bands that were of greater intensity than surrounding ones were considered to represent more than one digest fragment.

\section{RESULTS}

The PFGE analysis of $S$. epidermidis, $S$. caprae, $S$. capitis subsp. capitis, and $S$. capitis subsp. ureolyticus DNA showed distinct species and subspecies SmaI digest fragment patterns. $S$. epidermidis showed the greatest diversity in fragment patterns of the three species (Fig. 2 and 3). A total of 17 to 22 fragments were detected; they ranged in size from 8 to $630 \mathrm{~kb}$. MAW 815 and MAW 815 (91) represent the same strain and were collected from the forehead and anterior nares, respectively, of a patient receiving topical clindamycin therapy. MAW 815 was collected in 1981, whereas MAW 815 (91) was collected in 1991. These isolates represented the predominant $S$. epidermidis strain found on the patient. The fragment patterns of these two isolates were similar except for the positions of 3 of the 20 fragments. The genome sizes were the same.

S. epidermidis CB 877 isolates were obtained from a patient receiving topical clindamycin. $\mathrm{CB} 877-4$ was collected from the anterior nares. CB 877-6 was collected 4 weeks later from the inguinal-perineal area. The strain to which these isolates belong was the predominant strain found on this patient. The isolates had identical SmaI digest fragment patterns, except for the position of a single unshared fragment. It was determined that CB 877-4 has a fragment of approximately $243 \mathrm{~kb}$, whereas CB 877-6 has a fragment of approximately $293 \mathrm{~kb}$, for a difference in size of $50 \mathrm{~kb}$. The original identification of each MAW and CB isolate mentioned above was based on numerous phenotypic and plasmid characteristics (described in Materials and Methods) used for strain identification. Isolates belonging to the same strain had identical characteristics.

The DNA fragment pattern of $S$. caprae strains (Fig. 2 and 3 ) is more highly conserved than that of $S$. epidermidis. Table 2 lists the fragments conserved among species and subspecies as observed in this study. Approximately one-half of the $S$. caprae fragments were conserved, whereas only about $20 \%$ of the $S$. epidermidis fragments were conserved. A total of 17 to 28 fragments were detected for $S$. caprae, which ranged in size from about 3 to $533 \mathrm{~kb}$. The isolates were obtained from several different localities, demonstrating that the conserved DNA fragment pattern is not confined to one geographical area. Strains $143.22,141.15$, and 143.15 were collected from two different goat herds in Nouzilly, France. The remaining isolates were collected from human clinical specimens. The goat isolates had a fragment pattern different from that of the human isolates but shared fragments of $388,32,24$, and $22 \mathrm{~kb}$ with human isolates (Table 2). Concurrently, Bannerman et al. (2) observed similar results with goat and human $S$. caprae isolates, and they observed a similar level of conservation of fragment patterns when either SmaI or EagI digestion was used.

The DNA fragment patterns of $S$. capitis subsp. capitis and $S$. capitis subsp. ureolyticus are both highly conserved, but they are quite different from each other (Fig. 2 and 3; Table 2). For $S$. capitis subsp. capitis 20 to 23 fragments were identified. They ranged in size from about 5 to $700 \mathrm{~kb}$. Thirteen fragments were shared by all strains examined. These strains were obtained from a variety of geographical areas in the United States.

The DNA fragment pattern of $S$. capitis subsp. ureolyticus showed 18 to 19 fragments ranging in size from 5 to $463 \mathrm{~kb}$. The fragment pattern of $S$. capitis subsp. ureolyticus is the most highly conserved of the patterns for the four taxa examined. With the exception of those of four strains (Fig. 2, lanes 1, 9, 10 , and 13) all fragment patterns were identical. In the exceptional strains only one or two band differences were noted. S. capitis subsp. ureolyticus shared fragments of 89,82 , $54,35,19,7$, and $5 \mathrm{~kb}$ with $S$. capitis subsp. capitis (Table 2).

The average estimated genome size of each of the species and subspecies described above is shown in Table 3. The genome sizes of these species are somewhat smaller than that reported for Staphylococcus aureus (21). The genome sizes of

TABLE 3. Estimated genome size of Staphylococcus species and subspecies

\begin{tabular}{llrr}
\hline & & \multicolumn{2}{c}{ Genome size (kb) } \\
\cline { 3 - 4 } \multicolumn{1}{c}{ Species and subspecies } & Host & Mean & $\begin{array}{r}\text { Standard } \\
\text { deviation }\end{array}$ \\
\hline S. aureus $^{a}$ & & 2,741 & 277 \\
S. epidermidis $_{\text {S. capitis } \text { subsp. capitis }}$ & Human & 2,364 & 119 \\
S. capitis subsp. ureolyticus & Human & 2,456 & 71 \\
S. caprae & Human & 2,276 & 90 \\
$S$. caprae & Human & 2,600 & 157 \\
\hline
\end{tabular}

${ }^{a}$ Results reported by Prevost et al. (21). 
various strains of $S$. capitis are more uniform than those of the other species examined in this study.

\section{DISCUSSION}

$S$. epidermidis is the most abundant and widely distributed Staphylococcus species on the human skin. It is found in greatest numbers in the moist anterior nares, axillae, inguinalperineal area, and toe webs, but it also can be found on drier skin areas (10). The great adaptability of this species may account for the large amounts of chromosome fragment polymorphisms observed among isolates. In support of this principle, two predominant strains of $S$. epidermidis, MAW 815 and CB 877, exhibited some chromosome polymorphism within subpopulations isolated from different body sites and at different times. This species also demonstrates a wide variety of biotypes (9).

Strains of $S$. caprae gathered from the milk of goats showed some deviation from the human $S$. caprae strains with respect to their DNA fragment patterns. This divergence in pattern may reflect some evolutionary change within the species in the process of changing hosts. It is quite conceivable that humans and goats have come to share some of their bacteria during the course of a long association throughout the history of agriculture.

The two most closely related taxa in this study were $S$. capitis subsp. capitis and $S$. capitis subsp. ureolyticus, yet these subspecies showed very different DNA fragment patterns. These subspecies have approximately $79 \%$ DNA-DNA homology under stringent conditions and $89 \%$ homology under optimal conditions (3). When the DNA fragment patterns were analyzed, the relatively high degree of DNA homology was not apparent. The marked reduction in chromosome polymorphism compared with that of the related species $S$. epidermidis may be associated with the restricted habitat range of these subspecies and limited biotype variability (9). Chromosome fragment patterns are also highly conserved within the genus Brucella and especially in Brucella melitensis (1). S. capitis is primarily found on the head, though occasionally $S$. capitis subsp. ureolyticus may colonize other body sites on certain individuals following antibiotic therapy (12). These features may reflect less adaptability within the species.

It is apparent from our results that PFGE analysis can be used as an epidemiological tool for the identification of different $S$. epidermidis strains (7) but that this method would have limited use for monitoring strains or clones of $S$. caprae or S. capitis.

\section{ACKNOWLEDGMENTS}

We thank Keith Everett for scanning our polaroid negatives with the Soft Laser Densitometer and Jonathan Saluta for his technical assistance. We also thank L. W. Ayers for providing us with various human $S$. caprae strains used in this study.

\section{REFERENCES}

1. Allardet-Servent, A., G. Bourg, M. Ramuz, M. Pages, M. Bellis, and G. Roizes. 1988. DNA polymorphism in strains of the genus Brucella. J. Bacteriol. 170:4603-4607.

2. Bannerman, T. L., L. W. Ayers, and W. E. Kloos. 1993. Unpublished results.

3. Bannerman, T. L., and W. E. Kloos. 1991. Staphylococcus capitis subsp. ureolyticus subsp. nov. from human skin. Int. J. Syst. Bacteriol. 41:144-147.

4. Brenner, D. J., G. R. Fanning, A. Rake, and K. E. Johnson. 1969. A batch procedure for thermal elution of DNA from hydroxyapatite. Anal. Biochem. 28:447-459.

5. Chesneau, O., A. Morvan, F. Grimont, H. Labischinski, and N. El
Solh. 1993. Staphylococcus pasteuri sp. nov., isolated from human, animal, and food specimens. Int. J. Syst. Bacteriol. 43:237-244.

6. Devriese, L. A., B. Poutrel, R. Kilpper-Balz, and K. H. Schleifer. 1983. Staphylococcus gallinarum and Staphylococcus caprae, two new species from animals. Int. J. Syst. Bacteriol. 33:480-486.

7. Goering, R. V., and T. D. Duensing. 1990. Rapid field inversion gel electrophoresis in combination with an rRNA gene probe in the epidemiological evaluation of staphylococci. J. Clin. Microbiol. 28:426-429.

8. Goering, R. V., and M. A. Winters. 1992. Rapid method for epidemiological evaluation of gram-positive cocci by field inversion gel electrophoresis. J. Clin. Microbiol. 30:577-580.

9. Kloos, W. E. 1986. Community structure of coagulase-negative staphylococci in humans, p. 132-138. In L. Leive (ed.), Microbiology1986. American Society for Microbiology, Washington, D.C.

10. Kloos, W. E. 1986. Ecology of human skin, p. 37-50. In P. A. Mardh and K. H. Schleifer (ed.), Coagulase-negative staphylococci. Almqvist and Wiksell International, Stockholm.

11. Kloos, W. E. 1990 . Systematics and the natural history of staphylococci. 1. J. Appl. Bacteriol. Symp. Suppl. 69:255-375.

12. Kloos, W. E., H. A. Berkhoff, E. Muller, and T. L. Bannerman. 1992. Relationship between cutaneous persistence in natural populations of coagulase-negative staphylococci and their ability to produce catheter infections, biofilm, and polysaccharide adhesin, B-240, p. 66. Abstr. 92nd Gen. Meet. Am. Soc. Microbiol. 1992.

13. Kloos, W. E., and D. W. Lambe, Jr. 1991. Staphylococcus, p. 222-237. In A. Balows, W. J. Hausler, Jr., K. L. Herrmann, H. D. Isenberg, and H. J. Shadomy (ed.), Manual of clinical microbiology, 5th ed. American Society for Microbiology, Washington, D.C.

14. Kloos, W. E., and K. H. Schleifer. 1975. Isolation and characterization of staphylococci from human skin. II. Descriptions of four new species: Staphylococcus warneri, Staphylococcus capitis, Staphylococcus hominis, and Staphylococcus simulans. Int. J. Syst. Bacteriol. 25:62-79.

15. Kloos, W. E., K. H. Schleifer, and F. Götz. 1991. The genus Staphylococcus, p. 1369-1420. In A. Balows, H. G. Truper, M. Dworkin, W. Harder, and K. H. Schleifer (ed.), The prokaryotes, 2nd ed. Springer-Verlag, New York.

16. Kloos, W. E., T. G. Tornabene, and K. H. Schleifer. 1974. Isolation and characterization of micrococci from human skin, including two new species: Micrococcus lylae and Micrococcus kristinae. Int. J. Syst. Bacteriol. 24:79-101.

17. Kloos, W. E., and J. F. Wolfshohl. 1979. Evidence for deoxyribonucleotide sequence divergence between staphylococci living on human and other primate skin. Curr. Microbiol. 3:167-172.

18. McClelland, M., R. Y. Jones, and M. Nelson. 1987. Restriction endonucleases for pulsed field mapping of bacterial genomes. Nucleic Acids Res. 15:5985-6005.

19. Pfaller, M. A., and L. A. Herwaldt. 1988. Laboratory, clinical, and epidemiological aspects of coagulase-negative staphylococci. Clin. Microbiol. Rev. 1:281-299.

20. Pfaller, M. A., and R. J. Hollis. 1989. Use of plasmid profiles and restriction endonuclease analysis of plasmid DNA as epidemiologic and diagnostic tools in the clinical microbiology laboratory. Clin. Microbiol. Newsl. 11:137-142.

21. Prevost, G., B. Jaulhac, and Y. Piemont. 1992. DNA fingerprinting by pulsed-field gel electrophoresis is more effective than ribotyping in distinguishing among methicillin-resistant Staphylococcus aureus isolates. J. Clin. Microbiol. 30:967-973.

22. Schleifer, K. H., and W. E. Kloos. 1975. Isolation and characterization of staphylococci from human skin. I. Amended descriptions of Staphylococcus epidermidis and Staphylococcus saprophyticus and descriptions of three new species: Staphylococcus cohnii, Staphylococcus haemolyticus, and Staphylococcus xylosus. Int. J. Syst. Bacteriol. 25:50-61.

23. Tanasupawat, S., Y. Hashimoto, T. Ezaki, M. Kozaki, and K. Komagata. 1992. Staphylococcus piscifermentans sp. nov., from fermented fish in Thailand. Int. J. Syst. Bacteriol. 42:577-581.

24. Webster, J., R. Hubner, E. Cole, J. Bruce, T. Bannerman, D. Ballard, and W. Kloos. 1993. The Staphylococcus sciuri species group described by EcoR1 fragments containing ribosomal RNA sequences, with recognition of Staphylococcus vitulus sp. nov., R-14, p. 295. Abstr. 93rd Gen. Meet. Am. Soc. Microbiol. 1993. 